\title{
Lightweight mortars containing expanded polystyrene and paper sludge ash
}

\author{
V. Ferrándiz-Mas* ${ }^{*}$ a,, T. Bond ${ }^{b}$, E. García-Alcocel $^{\mathrm{a}}$, C.R. Cheeseman ${ }^{\mathrm{b}}$ \\ ${ }^{a}$ Departamento de Construcciones Arquitectónicas. Universidad de Alicante. Alicante. Spain. \\ ${ }^{b}$ Department of Civil and Environmental Engineering, Imperial College London, 7 South Kensington \\ Campus, London SW7 2AZ, United Kingdom
}

\begin{abstract}
The objective of this research was to develop lightweight cement mortars with good thermal-insulation properties by incorporating expanded polystyrene (EPS) and paper sludge ash (PSA), both of which are problematic waste materials. The mortars formed had low thermal conductivity and low bulk density compared to control samples. Ground EPS produced lower thermal conductivity samples than powdered EPS. Resource efficient mortars containing up to $20 \%$ PSA, and $60 \%$ of EPS are considered suitable for use in rendering and plastering applications.
\end{abstract}

Keywords: rendering mortar, supplementary cementitious material, waste, paper sludge ash, expanded polystyrene, lightweight aggregate, thermal conductivity.

\section{Introduction}

The resource efficiency of construction and building materials is a major contemporary issue facing industry. Many regions of the world are experiencing problems disposing of increasing amounts of municipal solid waste and miscellaneous industrial wastes. In addition, given the major $\mathrm{CO}_{2}$ emissions associated with the Portland cement manufacture process, much research in the field of construction materials is focused on using environmentally-sustainable raw materials. Consequently, a considerable body of literature has accumulated in recent years documenting the behaviour of construction materials in which traditional components have been replaced by waste materials, either as supplementary cementitious materials or as aggregate. These materials include ground granulated blast-furnace slag 
(1), coal fly ash (2), silica fume (3), glass (4-7), paper sludge (8), rubber, micronized tyre fibre and milled

husk ash (13), wheat straw ash (14) and sugarcane bagasse ash (15). Incorporating waste materials alters the mechanical and physical properties and durability of cementitious materials. In this research, paper sludge ash (PSA) was used as a supplementary cementitious material and expanded polystyrene was used as lightweight aggregate.

The pulp and paper industry in Europe produces 11 million tonnes of paper sludge waste per annum (16). During processing paper sludge is often dewatered and combusted to recover energy and reduce the volume of waste requiring disposal to landfill. This produces paper sludge ash (PSA), with 10-15 kg generated for every tonne of paper manufactured (16). Although the composition of PSA varies, it typically contains lime $(\mathrm{CaO})$, silica $\left(\mathrm{SiO}_{2}\right)$ and alumina $\left(\mathrm{Al}_{2} \mathrm{O}_{3}\right)$ and for this reason has been used as a supplementary cementitious material $(\mathrm{SCM})(8,17)$. Paper sludge contains a high proportion of organic matter, in the form of cellulose, as well as inorganic compounds, such as clays and calcium carbonate (18). The mineralogical composition of PSA depends on the combustion temperature. If combustion occurs in the range of $700-750{ }^{\circ} \mathrm{C}$, clay minerals in the paper sludge such as kaolinite will be transformed into metakaolinite (MK) (18) and the PSA will behave as a pozzolanic material $(8,17,19)$. However, if the PSA is produced at higher temperatures between $850-1200^{\circ} \mathrm{C}$ then it does not contain any observable MK and the PSA behaves as a hydraulic material (20-22), and this is the case of the PSA used in this research.

Expanded polystyrene (EPS) is a low-density, inert, hydrocarbon thermoplastic that is extensively used in packaging and thermal insulation (23). EPS is stable in the presence of most other chemicals with the exception of concentrated acids, organic solvents and saturated aliphatic compounds which dissolve EPS (24). Complete combustion of EPS in an atmosphere with sufficient oxygen produces carbon dioxide $\left(\mathrm{CO}_{2}\right)$ and water. If oxygen is limited, the combustion products are mainly carbon monoxide gas $(\mathrm{CO})$ and soot particles (C) (25). No references were found to emission of hazardous organic volatile compounds from EPS and when EPS is used in mortars it is contained in an inflammable inorganic matrix. 
Over 30 countries have signed an international agreement to maximise reuse and recycling of EPS (24).

Lightweight concretes manufactured with EPS have been used in a range of applications including rendering panels, flooring, concrete blocks, road pavements and in railway and marine structures (2629). The literature on concrete containing EPS has focused on characterising the mechanical properties of these materials and has investigated the effects of using EPS with different grain sizes, organic additives and other additions such as fly ash and silica fume $(10,30,31)$. Other studies have characterised the mechanical and thermal properties of concrete containing EPS (32). EPS beads have been used to design thermally insulating composites made with foamed cement pastes, using additives to prevent segregation and improve adherence (33). However, only a limited amount of research has investigated commercial EPS $(34)$ or various types of waste EPS $(35,36)$ in cement mortars. More recent work reported the properties of cement mortars where Portland cement (CEM I) was replaced by cements with lower clinker (CEM II and CEM III) (37). Due to the high volume of waste EPS and the environmental issues associated with EPS it is important to develop new beneficial reuse applications for this material that exploit lightweight and thermal insulating properties.

The use of lightweight aggregates reduces the thermal conductivity of cement-based materials (38). The thermal conductivity of construction products is an increasingly important parameter that significantly influences the energy associated with heating and cooling buildings. The impact of different materials on the thermal conductivity of cement based materials, including cellulose and glass fibre, mineral wool, polystyrene, urethane foam and vermiculite (39-43) has been investigated. Nonetheless, there remains a requirement for high thermally-insulating mortars with good dimensional stability in the construction industry. The use of industrial by-products to reduce the thermal conductivity of cement-based materials has significant advantages associated with improved resource efficiency. Relevant research has included work on lightweight cement-based materials containing waste glass, fly ash, silica fume, tyre rubber, expanded clay, wood and paper (44-48).

The objective of this research was to evaluate the influence of PSA and EPS on the thermal properties of cement mortars and produce resource efficient lightweight cement mortars with thermal-insulating 
properties. These mortars in which PSA acts as an SCM and EPS as a lightweight aggregate have potential applications as sustainable masonry and plaster materials. Two types of waste EPS, ground and powdered, were used as lightweight aggregates. This is in contrast to previous research which has used commercial EPS spheres rather than waste EPS. In addition, up to $80 \%$ by mass of Portland cement was replaced by PSA, whereas in previous research only up to $20 \%$ of cement was replaced by PSA $(49,50)$. The thermal conductivity, workability, bulk density and compressive strength of mortars are reported.

\section{Materials and methods}

\subsection{Materials}

Portland cement (type CEM II /A-LL 32,5R, Lafarge Cement UK) and silica sand with a maximum particle size of $2 \mathrm{~mm}$, a bulk density of $1.60 \mathrm{~g} / \mathrm{cm}^{3}$ complying with European standard EN 196-1:2005 were used (51). PSA was obtained from a major paper mill producing newsprint operating in SE England. The chemical composition of the CEMII and PSA, showing major components as oxides determined by XRF are shown in Table 1. The specific surface determined using the Blaine Method according to standard EN 196-6 (52) of PSA and CEM II were $2060 \mathrm{~cm}^{2} / \mathrm{g}$ and $4700 \mathrm{~cm}^{2} / \mathrm{g}$, respectively. The density of PSA was 2.7 $\mathrm{g} / \mathrm{cm}^{3}$ and CEM II was $3.2 \mathrm{~g} / \mathrm{cm}^{3}$. Figure 1 shows the particle size distribution of PSA and cement obtained by laser diffraction (Coulter LS 230). The particle size distribution for PSA was multimodal with maximums at $0.5 \mu \mathrm{m}, 4.0 \mu \mathrm{m}$ and $55.1 \mu \mathrm{m}$. The particle size distribution for CEM II was also multimodal with maximums at $0.3 \mu \mathrm{m}, 18.0 \mu \mathrm{m}$ and $127.6 \mu \mathrm{m}$. The maximum particle size present in both PSA and CEM II was approximately $200 \mu \mathrm{m}$.

Figure 2 shows an SEM micrograph (Hitachi S-3000N with BRUKER X-Flash 3001 detector) of a large PSA particle. This shows a porous, heterogeneous structure with high surface roughness resulting from the agglomeration of individual mineral grains produced during the combustion process (22). Ground and powdered EPS were supplied by “Asociación Nacional de Poliestireno Expandido" (ANAPE (Madrid, Spain) (24). These had a loss of ignition of $100 \%$, softening point between 80 and $100^{\circ} \mathrm{C}$, and 
water absorption by immersion, after 28 days, between 1 and $3 \%$ volume. The differences between the two types of EPS mainly related to particle size. Both were obtained by mechanical grinding and sieving waste EPS. $100 \%$ of the ground EPS particles passed through a $1 \mathrm{~mm}$ sieve and the bulk density was $0.013 \mathrm{~g} / \mathrm{cm}^{3}$. All the particles of powdered EPS passed through a $0.5 \mathrm{~mm}$ sieve and this had a slightly higher bulk density of $0.022 \mathrm{~g} / \mathrm{cm}^{3}$.

An air-entraining agent (A, BASF Rheomix 934), a water retaining additive ( $R$, Hydroxypropyl methylcellulose TER CELL HPMC 15 MS PF), a superplastizicer (S, BASF Rheomix GT 205 MA) and a dispersible polymer (V, VINNAPAS 5028E) were also used to form optimum mortar samples.

\subsection{Preparations of mortars}

All the mortar samples were produced following the procedures described in EN 196-1 (51). The mix designs are shown in Table 2. The samples were prepared with a binder/sand ratio (by weight) of 1:3 (i.e. 1 part of binder (CEM II/PSA) to 3 parts of silica sand), with PSA systematically replacing up to $80 \%$ by mass of CEM II. The EPS was dosed as an addition to the total mortar volume, expressed as the apparent volume of sand ( $\mathrm{v} / \mathrm{v} \%)$. Additives were added to mortars as a percentage of the weight of the total binder (w/w\%).

The optimum dosage of EPS and the additives used in the mixes ( $A, R, S$ and $V)$ was determined in a previous study (37). Preparation of mortars with no additives or one additive failed to achieve the desired physical, mechanical and durability properties $(35,36)$. The software NEMRODW $(53)$ was used to build and analyse the D-optimal design to determine the optimal composition of mortars containing ground and powdered EPS used in the current study. These optimal mortars are denoted as gOPSA and pOPSA (Table 2) and comply with the EU standards for masonry mortars, rendering and plaster $(54,55)$. Optimal EPS dosage when silica sand and CEM II were used, was determined as $60 \mathrm{v} / \mathrm{v} \%$, for both ground and powdered EPS. Further, the optimal additives mixes selected were $0.4 \% \mathrm{~A}, 0.1 \% \mathrm{R}, 0.5 \% \mathrm{~S}$ and $6 \% \mathrm{~V}$ for the EPS ground and $0.8 \% \mathrm{~A}, 0.1 \% \mathrm{R}, 0.8 \% \mathrm{~S}$ and $6 \% \mathrm{~V}$ for EPS powdered (Table 2). 
In addition, three control mortars were produced in order to compare with obtained results and analyse

control mortar did not contain any EPS or PSA (control C). The second control contained no EPS and 20\% PSA (control P). The third control mortar contained 20\%PSA, no EPS and an additive mix of $0.8 \% \mathrm{~A}, 0.1 \%$ $\mathrm{R}, 0.8 \% \mathrm{~S}$ and $6 \% \mathrm{~V}$ (control PA).

The quantity of water in the mix was controlled to maintain constant workability for different types of samples, as defined by EN 1015-2:1998 (56). Mortars with a bulk density above $1200 \mathrm{~kg} / \mathrm{cm}^{3}$ were prepared with a flow table spread of $175 \pm 10 \mathrm{~mm}$. For lower density mortars with bulk densities between 600 and $1200 \mathrm{~kg} / \mathrm{cm}^{3}$, the mix water was controlled to give a flow table spread of $160 \pm 10 \mathrm{~mm}$. Triplicate $50 \times 50 \times 50 \mathrm{~mm}$ samples were cast and kept in moulds for 24 hours at $23 \pm 2{ }^{\circ} \mathrm{C}$, during which time they were covered with a plastic film to minimize water evaporation. They were then removed from the moulds and cured underwater for 28 days at $23 \pm 2{ }^{\circ} \mathrm{C}(20,22,63)$. This fact, together with the requirements of the standards for rendering, plastering and masonry that require compressive strength at 28 curing time $(54,55)$, justifies the curing time of 28 days used prior to testing compressive strength. Previous studies have shown that the thermal conductivity of cementitious materials can increase by up to $5 \%$ for each $1 \mathrm{wt} . \%$ of water retained in the material. Samples were therefore dried at $70 \pm 2{ }^{\circ} \mathrm{C}$ for 7 days prior to thermal conductivity testing (57).

\subsection{Methods for mortar characterisation}

\subsubsection{Workability, bulk density and thermal conductivity testing}

The flow table method (EN 1015-3:2007 (58)) was used in order to determine the amount of PSA and water in each mortar. The amount of water was that needed to achieve a workability between the values given in EN 1015-2 (56) (see Section 2.2).

Volumetric densities of dried mortar samples were obtained from the sample mass and dimensions. These samples were then used to determine thermal conductivity using a TT-TC Probe (Therm Test Inc.). This is a non-destructive test based on the Mathis modified hot-wire technique (59) that measures the 
temperature rise at a defined distance from a linear heat source in contact with the test material (60). The heat source is assumed to have a constant and uniform output along the length of the test sample and the thermal conductivity is then derived directly from the resulting change in temperature over a known time interval (61). This technique has previously been used to evaluate the thermal conductivity of cement mortars and pastes (62).

\subsubsection{Strength testing and microstructural analysis}

The compressive strengths of wet mortar samples were determined after 28 days curing using a hydraulic press (Controls Automax 5 series) following EN 196-1 (51). The microstructure of selected samples was studied by examining fracture surfaces using SEM (Hitachi S-3000N with BRUKER X-Flash 3001 detector).

\section{Results and discussion}

\subsection{Workability test}

Workability tests were used to determine the appropriate water/binder ratio given in Table 2.

Workability ranges for mortars with a fresh bulk density above $1200 \mathrm{~kg} / \mathrm{cm}^{3}$ were prepared with a flow table spread of $175 \pm 10 \mathrm{~mm}$, while for lower density mortars with fresh bulk densities between 600 and $1200 \mathrm{~kg} / \mathrm{cm}^{3}$ the mix water was controlled to give a flow table spread of $160 \pm 10 \mathrm{~mm}$ (56). Figure 3 shows the relationship between mortar workability and paper sludge addition with the water/binder ratio. This relationship was inversely proportional, i.e. as the workability reduced with increasing PSA addition, the water/binder ratio increased from 0.6 for up to $20 \mathrm{wt} . \%$ PSA additions to 1.3 when 80 wt.\% of CEM II was replaced by PSA.

The spread on the flow table for control mortar C (O\%EPS, 0\% PSA) was $193 \pm 2 \mathrm{~mm}$. This significantly decreased to $127 \pm 1 \mathrm{~mm}$ for samples containing $20 \%$ PSA (control mortar P) when the water/binder ratio remained constant at 0.6 . This equates to a reduction in workability of $34 \%$. However, the workability only reduced by $7 \%$ for control mortar PA that contained $20 \mathrm{wt} . \%$ PSA and the mix of additives given in 
Table $2(0.8 \% \mathrm{~A} / 0.1 \% \mathrm{R} / 0.8 \% \mathrm{~S} / 6 \% \mathrm{~V})$. These results with the control mortars without additives ( $\mathrm{C}$ and $\mathrm{P})$

highlight the requirement of adding more water and/or working with additives (Table 2 ) in order to achieve compliant workability values (56). The significant porosity in PSA could have a negative impact on the workability of cement-based materials. The mix water used to make mortars is absorbed by the interconnected open porosity of PSA, and this causes a marked reduction in workability which required the use of plasticizer or additional water (63).

When mortars contained EPS but no PSA (types gOPSA and pOPSA), the reduction in workability was reduced (1.5\% for EPS ground and 5\% for EPS powdered) compared with control mortar C (0\%EPS, 0\%PSA). Nevertheless, a higher water/binder ratio was required when mortars contained PSA (Figure 3) to achieve the target workability. Higher PSA contents needed higher water/binder ratios. For example, to obtain a flow table spread of $180 \pm 1 \mathrm{~mm}$ for $10 \%$ PSA and $60 \%$ EPS ground, a water/binder ratio of 0.60 was required. However, to obtain the same workability value of $180 \pm 1 \mathrm{~mm}$ for $30 \%$ PSA and the same EPS content (60\%EPSground), a water/binder of 0.75 was required.

There were clear differences between the two types of EPS. With powdered EPS it was possible to replace up to $50 \%$ of the cement while still keeping within workability limits. However using ground EPS, it was possible to replace up to $80 \%$ of cement. Although the workability of the mortars containing $80 \%$ of ground EPS was relatively low at $159 \mathrm{~mm}$, these mortars had the lowest bulk density, and for this reason the value obtained for the flow table spread were acceptable.

\subsection{Thermal Conductivity and dry bulk density}

Figure 4 shows the variation in thermal conductivity with PSA addition for mortars prepared using ground and powdered EPS. The presence of PSA in mortars caused significant reductions in thermal conductivity. Addition of $20 \%$ PSA caused a $23 \%$ reduction in thermal conductivity, relative to the control mortar C (0\%EPS, 0\%PSA). The largest reduction in thermal conductivity for mortars without EPS (control mortars) was for control mortar PA. This had a reduction of $55 \%$ compared to the control mortar C (0\% EPS, 0\%PSA). This decrease in thermal conductivity is due to the significant reduction in 
bulk density (Table 3 ) of this mortar due to the presence of the air-entraining agent (A). This demonstrates the strong correlation between thermal conductivity and bulk density.

The presence of EPS in mortars significantly reduced the thermal conductivity, as can be seen by comparing control mortar $\mathrm{C}$ with mortars containing EPS but no PSA, such as samples gOPSA and pOPSA (Figure 4, Table 2). Reductions in thermal conductivity of $60 \%$ for ground EPS and $47 \%$ for powdered EPS were observed. The effect of the type of EPS used was discussed in previous work on the mechanical, physical and microstructural properties of mortars made with EPS as lightweight aggregate $(33,34)$. The higher thermal conductivity of mortars containing EPS powdered compared to mortars containing EPS ground is due to the higher bulk density. This is due to both the higher density of EPS powdered and its morphology. The process in which waste EPS particles are powdered reduces the entrained air which is a characteristic of EPS (Figure 5a). However, in the case of ground EPS the particles still contain air, and this explains the lower bulk density (Figure $5 b$ ). When mortars contained both types of waste (EPS and PSA), these differences between the types of EPS continued. The thermal conductivity of mortars made with $10 \%$ of PSA was $0.63 \pm 0.11 \mathrm{~W} / \mathrm{m} \cdot \mathrm{K}$ for powdered EPS, and $0.57 \pm 0.01 \mathrm{~W} / \mathrm{m} \cdot \mathrm{K}$ for ground EPS. This agrees with the lower bulk density of mortars containing ground EPS and $10 \%$ PSA $\left(1.05 \pm 0.01 \mathrm{~g} / \mathrm{cm}^{3}\right)$ compared to the bulk density of mortars containing powdered EPS and also $10 \%$ PSA $\left(1.17 \pm 0.01 \mathrm{~g} / \mathrm{cm}^{3}\right)$. For both types of EPS there was a general decrease in thermal conductivity as the proportion of PSA increased. With $30 \%$ PSA, reductions in thermal conductivity of $70 \%$ for ground EPS ground and $68 \%$ for powdered EPS were obtained compared to control mortar C. Reductions of $23 \%$ for ground EPS and $39 \%$ for powdered EPS were obtained for 30\% PSA samples compared with mortars containing EPS but no PSA (i.e. gOPSA and pOPSA respectively).

Control mortar PA also had reduced thermal conductivity compared to control mortars $\mathrm{C}$ and $\mathrm{P}$, the respective values being $0.72 \pm 0.08,1.60 \pm 0.11$ and $1.23 \pm 0.12 \mathrm{~W} / \mathrm{m} \cdot \mathrm{K}$. This is because of the presence of additives, in particular the air-entraining agent, which also reduces density. The respective bulk densities were $1.23 \pm 0.07,2.05 \pm 0.01$ and $1.98 \pm 0.01 \mathrm{~g} / \mathrm{cm}^{3}$ for mortars PA, C and P (Table 3). As the loading of ground PSA increased above $30 \%$, reductions in thermal conductivity were relatively minor but 
consistent. For ground EPS mortars containing the highest dosage of PSA (70\% and $80 \%)$, the thermal conductivity decreased by $77 \%$ compared to the control mortar C (0\%EPS, 0\%PSA), and $42 \%$ compared to g0PSA (60\%EPS, 0\%PSA).

This data shows that increasing additions of PSA reduced the thermal conductivity. All mortars containing PSA had lower thermal conductivity than control mortars $\mathrm{C}$ and $\mathrm{P}$, which contained no PSA or EPS (C) and 20\% PSA and 0\%EPS (P). PSA reduces thermal conductivity in mortars because it is an inherently porous material.

\subsection{Compressive strength}

Figure 6 shows compressive strength data for samples after curing for 28 days. Compressive strength tended to decrease with PSA dosage. The compressive strength of control mortar P (0\% EPS, 20\% PSA) was approximately $5 \%$ less than control mortar C (0\%EPS, 0\%PSA). The additives in control mortar PA (0\% EPS, 20\%PSA, 0.8A/0.1R/0.8S/6V) caused a $79 \%$ reduction in strength compared to control mortar C (0\%EPS, 0\%PSA). A similar reduction of $84 \%$ was obtained for the gOPSA sample (60\% ground EPS, 0\%PSA, 0.4A/0.1R/0.5S/6V). The reduction in strength was not due to the amount of EPS in the samples but was caused by the additives used to obtain suitable workability.

A reduction in compressive strength of $65 \%$ compared to control mortar $C$ was observed for the same sample but with powdered EPS (pOPSA). This reduction was lower than for ground EPS despite the fact that the additives mix used for mortars containing powdered EPS had a higher amount of air-entraining agent than samples made with ground EPS. This highlights the differences between the two types of waste EPS. In general, smaller reductions in compressive strength compared to control mortars were obtained for mortars with powdered EPS than with ground EPS. These differences are consistent with the bulk density for each type of EPS (bulk density for powdered EPS and ground EPS, 0.022 and 0.013 $\mathrm{g} / \mathrm{cm}^{3}$ respectively), as well as the morphology of EPS (Figure 5). Consequently, the use of powdered EPS produces mortars with higher bulk density and higher compressive strength relative to those with ground EPS. 
For both types of EPS, samples with a 10\% PSA showed a reduction in compressive strength compared powdered EPS. Though the reduction for mortars with powdered EPS were higher than for ground EPS,

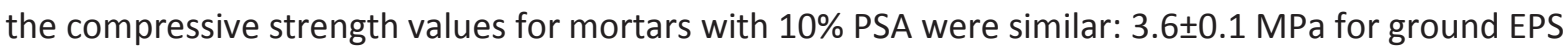
and 4.0 $\pm 0.2 \mathrm{MPa}$ for powdered EPS. However, the compressive strength of mortars was either improved or maintained when the dosage of PSA increased from $10 \%$ to $20 \%$ PSA. These results agree with previous studies on the compressive strength of mortars made with a commercial Portland cement (CEM I 52.5N), standard silica sand, a water/binder ratio of 0.5 , a mass ratio of binder to sand of $1: 3$ and up to $20 \%$ PSA replaced by cement (50). Figure 6 also shows a sharp decrease in compressive strength from $4.7 \pm 0.3$ to $1.0 \pm 0.1 \mathrm{MPa}(80 \%)$ on increasing the PSA content from $20 \%$ to $30 \%$ for mortars containing ground EPS. Furthermore, a lower decrease in strength, 21\%, was observed for mortars containing powdered EPS when the amount of PSA increased from 20 to $30 \%$. This highlights the advantages of using powdered EPS in terms of compressive strength.

Figure $5 \mathrm{~b}$ shows the fracture surface of a mortar sample g30PSA (30\% PSA, 60\% ground EPS, $0.4 \mathrm{~A} / 0.1 \mathrm{R} / 0.5 \mathrm{~S} / 6 \mathrm{~V})$, in which a ground EPS particle is visible. It can be seen how the EPS particle has a characteristic honeycomb structure, which gives this type of EPS low bulk density. Moreover, the cement paste in this sample had high porosity, which could be due to the additives, as well as the water/binder ratio for the samples containing 20\% PSA and 30\%PSA. In the case of mortars with $20 \%$ PSA (g20PSA) the water/binder ratio used was 0.6 , while for mortars containing 30\%PSA (g30PSA) the water/binder ratio used was 0.75 (Table 2). This increase in water/binder ratio caused a decrease in compressive strength. In addition, the high amount of PSA may cause the alkaline reserves of the cement to be consumed, leaving unreacted PSA. In this situation PSA is expected to behave as inert filler. The particle size range and variable composition of PSA is likely to result in variable hydration behaviour, in which some phases contribute to hydration products while other phases are inert (20). The results of compressive strength for the samples tested show a positive correlation with bulk density of these mortars. 


\subsection{Optimum mortars based on EU standards for rendering, plastering and masonry}

High compressive strength is less critical when mortars are used for masonry. The relevant EU standard specifies that type CS III mortars must have a compressive strength greater than $3.5 \mathrm{MPa}$ to be used for rendering and plastering (54). Therefore mortars containing up to $20 \%$ PSA, using either powdered or ground EPS are suitable for type CS III rendering and plastering application. However, type CS II mortars must have compressive strength of between 1.5 and 5.0 MPa. Mortars with up to 30\% PSA using powdered EPS and up to 20\% PSA with ground EPS are appropriate (Table 4). Type CS I mortars must have compressive strengths between 0.4 and $2.5 \mathrm{MPa}$ and for this application mortars containing between 30 and 60\% PSA and ground EPS and between 40 and 50\% PSA for powdered EPS are suitable. With respect to masonry mortar types $\mathrm{M} 1, \mathrm{M} 2.5, \mathrm{M} 5, \mathrm{M} 10, \mathrm{M} 15$ and $\mathrm{M} 20$ (55), PSA containing mortars are only suitable for M1 and M2.5 applications. For these classifications mortars containing up to $20 \%$ PSA for ground EPS, and up to 40\% PSA for powdered EPS are suitable. However, for M2.5 mortars containing up to $20 \%$ PSA for ground EPS and up to 30\% PSA for powdered EPS are appropriate.

\section{Conclusions}

The following conclusions resulted from this research:

(1) Mortars containing PSA and EPS had lower thermal conductivity than control mortars. For example, thermal conductivities of mortars containing $30 \%$ PSA were reduced by $70 \%$ for ground EPS and $68 \%$ for powdered EPS relative to the control mortars which contained neither PSA or EPS.

(2) Bulk densities of mortars were also reduced by PSA and EPS. In the case of mortars containing $30 \%$ PSA, densities were reduced by $45 \%$ for ground EPS and $42 \%$ for powdered EPS relative to the control mortar C.

(3) The reductions in compressive strength relative to control mortars were lower for mortars containing powdered EPS than with ground EPS. For mortars containing 30\% PSA the compressive strengths were reduced by $96 \%$ for ground EPS and $88 \%$ for powdered EPS relative to the control mortar C. 
(4) Ground EPS reduced thermal conductivity, bulk density and compressive strength more than an equivalent amount of EPS powdered.

(5) Mortars containing up to $20 \%$ PSA, and either powder or ground EPS are suitable for type CS III rendering and plastering applications in the EU. For type CS II applications, mortars containing up to $30 \%$ PSA (with powdered EPS) and up to 20\% PSA (with EPS ground) are appropriate. For CS I applications, mortars containing between $30-60 \%$ PSA (for ground EPS) and between $40-50 \%$ PSA (powdered EPS) are suitable.

(6) It is possible to manufacture sustainable mortars containing PSA and EPS that are in compliance with EU standards for rendering, masonry and plastering mortars.

\section{Acknowledgements}

The authors wish to thank the Spanish Ministry of Science and Innovation and European Union (FEDER) for project funding (BIA2007-61170), and the FPI scholarship (BES-2009-012166) award to Verónica Ferrándiz Mas which allowed her to develop her doctoral thesis. This research was carried out in the Civil and Environmental Engineering Department at Imperial College London, with funding from the Spanish Ministry of Economy and Competitiveness (EEBB-I-12-0574) to support Verónica Ferrándiz Mas. Charikleia Spathi is acknowledged for providing technical support to the research.

\section{References}

(1) Barnett SJ, Soutsos MN, Millard SG, Bungey JH. Strength development of mortars containing ground granulated blast-furnace slag: Effect of curing temperature and determination of apparent activation energies. Cem Concr Res 2006 3;36(3):434-440

(2) Kwan AKH, Li Y. Effects of fly ash microsphere on rheology, adhesiveness and strength of mortar. Constr Build Mater 2013 5;42(0):137-145

(3) Rao GA. Investigations on the performance of silica fume-incorporated cement pastes and mortars. Cem Concr Res 2003 11;33(11):1765-1770 
(4) Khmiri A, Chaabouni M, Samet B. Chemical behaviour of ground waste glass when used as partial cement replacement in mortars. Constr Build Mater 2013 7;44(0):74-80

(5) Matos AM, Sousa-Coutinho J. Durability of mortar using waste glass powder as cement replacement. Constr Build Mater 2012 11;36(0):205-215

(6) Pereira-de-Oliveira LA, Castro-Gomes JP, Santos PMS. The potential pozzolanic activity of glass and red-clay ceramic waste as cement mortars components. Constr Build Mater 2012 6;31(0):197-203

(7) Corinaldesi V, Gnappi G, Moriconi G, Montenero A. Reuse of ground waste glass as aggregate for mortars. Waste Manage 2005;25(2):197-201

(8) García R, Vigil de la Villa R, Vegas I, Frías M, Sánchez de Rojas MI. The pozzolanic properties of paper sludge waste. Constr Build Mater 2008;22(7):1484-1490

(9) Bignozzi MC, Saccani A, Sandrolini F. New polymer mortars containing polymeric wastes. Part 1. Microstructure and mechanical properties. Composites Part A: Applied Science and Manufacturing 2000 2;31(2):97-106

(10) Babu DS, Ganesh Babu K, Tiong-Huan W. Effect of polystyrene aggregate size on strength and moisture migration characteristics of lightweight concrete. Cement and Concrete Composites 2006 7;28(6):520-527

(11) Lanzón M, García-Ruiz PA. Lightweight cement mortars: Advantages and inconveniences of expanded perlite and its influence on fresh and hardened state and durability. Constr Build Mater 2008 8;22(8):1798-1806

(12) Topçu IB, Işıkdağ B. Effect of expanded perlite aggregate on the properties of lightweight concrete. J Mater Process Technol 2008 8/11;204(1-3):34-38

(13) Givi AN, Rashid SA, Aziz FNA, Salleh MAM. Contribution of rice husk ash to the properties of mortar and concrete: a review. Journal of American science 2010;6(3):157-165

(14) Al-Akhras NM, Abu-Alfoul BA. Effect of wheat straw ash on mechanical properties of autoclaved mortar. Cem Concr Res 2002 6;32(6):859-863

(15) Ganesan K, Rajagopal K, Thangavel K. Evaluation of bagasse ash as supplementary cementitious material. Cement and Concrete Composites 2007 7;29(6):515-524

(16) Monte MC, Fuente E, Blanco A, Negro C. Waste management from pulp and paper production in the European Union. Waste Manage 2009 1;29(1):293-308

(17) Frías M, García R, Vigil R, Ferreiro S. Calcination of art paper sludge waste for the use as a supplementary cementing material. Appl Clay Sci 2008 12;42(1-2):189-193

(18) Pera J, Amrouz A. Development of Highly Reactive Metakaolin from Paper Sludge. Adv Cem Based Mater 1998 3;7(2):49-56

(19) Vegas I, Frías M, Urreta J, San José JT. Obtaining a pozzolanic addition from the controlled calcination of paper mill sludge. Performance in cement matrices. Materiales de Construccion 2006;56(283):49-60 
(20) Bai J, Chaipanich A, Kinuthia JM, O'Farrell M, Sabir BB, Wild S, et al. Compressive strength and hydration of wastepaper sludge ash-ground granulated blastfurnace slag blended pastes. Cem Concr Res 2003 8;33(8):1189-1202

(21) Mozaffari E, O'Farrell M, Kinuthia JM, Wild S. Improving strength development of wastepaper sludge ash by wet-milling. Cement and Concrete Composites 2006 2;28(2):144-152

(22) Mozaffari E, Kinuthia JM, Bai J, Wild S. An investigation into the strength development of Wastepaper Sludge Ash blended with Ground Granulated Blastfurnace Slag. Cem Concr Res 2009 10;39(10):942-949

(23) Kan A, Demirboğa R. A new technique of processing for waste-expanded polystyrene foams as aggregates. J Mater Process Technol 2009 3/19;209(6):2994-3000

(24) http://www.anape.es (Web de la Asociación Nacional del Poliestireno Expandido). Accessed 06/02, 2013

(25) Doroudiani S, Omidian H. Environmental, health and safety concerns of decorative mouldings made of expanded polystyrene in buildings. Build Environ 2010 3;45(3):647-654

(26) Cook DJ. Expanded polystyrene beads as lightweight aggregate for concrete. Precast Concr 1973;4:691-693

(27) Bagon C, Frondistou-Yannas S. Marine floating concrete made with polystyrene expanded beads. Mag Concr Res 1976;28:225-229

(28) Perry SH, Bischoff PH, Yamura K. Mix details and material behaviour of polystyrene aggregate concrete. Mag Concr Res 1991;43:71-76

(29) Bischoff PH, Yamura K, Perry SH. Polystyrene aggregate concrete subjected to hard impact. Proc Inst Civ Eng 2 Res 1990;89:225-239

(30) Babu KG, Babu DS. Behaviour of lightweight expanded polystyrene concrete containing silica fume. Cem Concr Res 2003 5;33(5):755-762

(31) Tang WC, Lo Y, Nadeem A. Mechanical and drying shrinkage properties of structural-graded polystyrene aggregate concrete. Cement and Concrete Composites 2008 5;30(5):403-409.

(32) Bouvard D, Chaix JM, Dendievel R, Fazekas A, Létang JM, Peix G, et al. Characterization and simulation of microstructure and properties of EPS lightweight concrete. Cem Concr Res 2007 12;37(12):1666-1673

(33) Laukaitis A, Žurauskas R, Kerien $\doteq$ J. The effect of foam polystyrene granules on cement composite properties. Cement and Concrete Composites 2005 1;27(1):41-47

(34) Torres ML, García-Ruiz PA. Lightweight pozzolanic materials used in mortars: Evaluation of their influence on density, mechanical strength and water absorption. Cement and Concrete Composites 2009 2;31(2):114-119 
(35) Ferrándiz-Mas V, García-Alcocel E. Physical and Mechanical characterization of Portland cement mortars made with expanded polystirene particles addition (EPS). Materiales de Construcción 2012;62(308):547

(36) Ferrándiz-Mas V, García-Alcocel E. Durability of expanded polystyrene mortars. Constr Build Mater 2013;46:175-182

(37) Ferrándiz, V.; "Design of cement mortars with addition of expanded polystyrene (EPS) polymeric waste". Doctoral Thesis. Research in Sustainable Architecture and Urban Planning Program. University of Alicante, Alicante, 2013

(38) Khedari J, Suttisonk B, Pratinthong N, Hirunlabh J. New lightweight composite construction materials with low thermal conductivity. Cement and Concrete Composites 2001 2;23(1):65-70

(39) Zhou X-, Zheng F, Li H-, Lu C-. An environment-friendly thermal insulation material from cotton stalk fibers. Energy Build 2010;42(7):1070-1074

(40) Demharte A. Polyurethane rigid foam, a proven thermal insulating material for applications between $+130^{\circ} \mathrm{C}$ and $-196^{\circ} \mathrm{C}$. Cryogenics $1998 ; 38: 113-117$

(41) Vrána T, Björk F. Frost formation and condensation in stone-wool insulations. Constr Build Mater 2009;23(5):1775-1787

(42) Mihlayanlar E, Dilmaç S, Güner A. Analysis of the effect of production process parameters and density of expanded polystyrene insulation boards on mechanical properties and thermal conductivity. Materials and Design 2008;29(2):344-352

(43) Nicolajsen A. Thermal transmittance of a cellulose loose-fill insulation material. Build Environ 2005;40(7):907-914

(44) Ducman V, Mladenovic A, Šuput JS. Lightweight aggregate based on waste glass and its alkali-silica reactivity. Cem Concr Res 2002;32(2):223-226

(45) Fu X, Chung DDL. Effects of silica fume, latex, methylcellulose, and carbon fibers on the thermal conductivity and specific heat of cement paste. Cem Concr Res 1997;27(12):1799-1804

(46) Benazzouk A, Douzane O, Mezreb K, Laidoudi B, Quéneudec M. Thermal conductivity of cement composites containing rubber waste particles: Experimental study and modelling. Constr Build Mater 2008;22(4):573-579

(47) Bouguerra A, Ledhem A, De Barquin F, Dheilly RM, Quéneudec M. Effect of microstructure on the mechanical and thermal properties of lightweight concrete prepared from clay, cement, and wood aggregates. Cem Concr Res 1998;28(8):1179-1190

(48) Ng S-, Low K-. Thermal conductivity of newspaper sandwiched aerated lightweight concrete panel. Energy Build 2010;42(12):2452-2456

(49) Fava G, Ruello M, Corinaldesi V. Paper Mill Sludge Ash as Supplementary Cementitious Material. J Mater Civ Eng 2011 06/01; 2013/05;23(6):772-776 
(50) Vegas I, Urreta J, Frías M, García R. Freeze-thaw resistance of blended cements containing calcined paper sludge. Constr Build Mater 2009 8;23(8):2862-2868

(51) EN 196-1:2005 "Methods of testing cement. Part 1: Determination of strength

(52) EN 196-6: 2010 "Methods of testing cement. Part 6: Determination of fineness"

(53) Mathieu J, Nony J, Phan Tan Luu R. NemrodW v2007-03, LPRAI, Marseille, France

(54) EN 998-1:2003 "Specification for mortar for masonry. Part 1: Rendering and plastering mortar"

(55) EN 998-2:2001 "Specification for mortar for masonry. Part 2: Masonry mortar"

(56) EN 1015-2 "Methods of test for mortar for masonry. Parte 2: Bulk sampling of mortars and preparation of test mortars"

(57) Steiger RW, Hurd MK. LIGHTWEIGHT INSULATING CONCRETE FOR FLOORS AND ROOF DECKS. Concrete Construction - World of Concrete 1978;23(7):411-413, 415, 420, 422

(58) EN 1015-3:2007 "Methods of test for mortar for masonry. Part 3: Determination of consistence of fresh mortar (by flow table)"

(59) Schmidt K, Qiu X, Mathis N, Chaplin G. Evaluation of thermal interface materials using the modified hot wire technique. Procedings of the 16th International Thermal Expansion Symposium. Dinwiddie RB, White MA, McElroy DL, editors. 2006

(60) ASTM C-1113-99 (Reapproved 2004) Standard Test Method for thermal conductivity of refractories by hot wire (Platinum Resistance thermometer technique)

(61) Davis W. Hot-Wire Method for the measurement of thermal conductivity of refractory materials. In MaglicKD, Cezairliyan A, Peletsky VE, editors. Compendium of Thermophysical Property Measurements Methods, vol.1. Survey of Measurement Techniques, New York: London, Plenum Press; 1984, p. 161

(62) Olmeda J, Sánchez de Rojas MI, Frías M, Donatello S, Cheeseman CR. Effect of petroleum (pet) coke addition on the density and thermal conductivity of cement pastes and mortars. Fuel 2013 5;107(0):138-146

(63) Segui P, Aubert JE, Husson B, Measson M. Characterization of wastepaper sludge ash for its valorization as a component of hydraulic binders. Appl Clay Sci 2012 3;57(0):79-85 


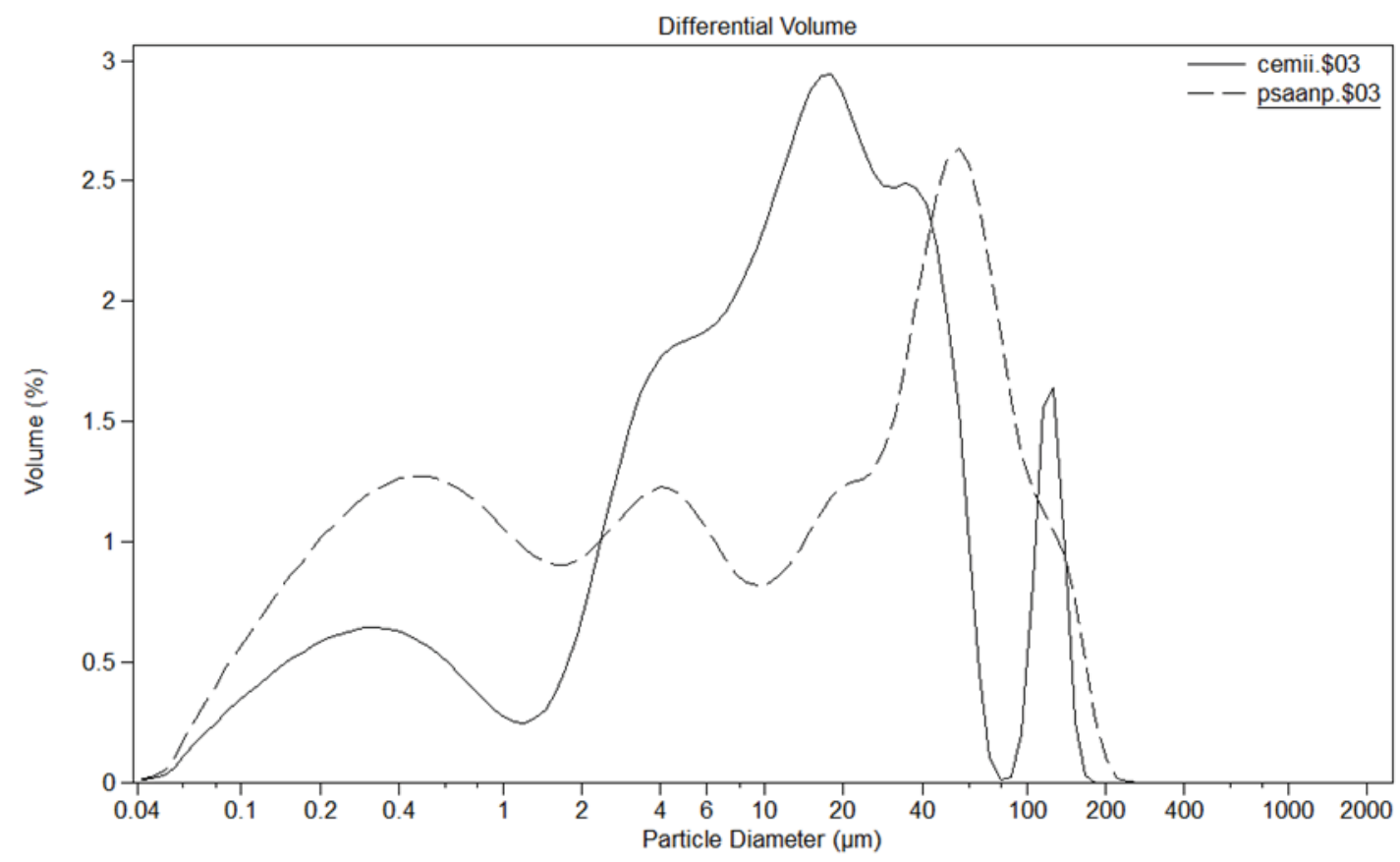

Figure 1. Particle size distribution for paper sludge ash (PSA) and CEM II by laser diffraction (Coulter LS 230) 


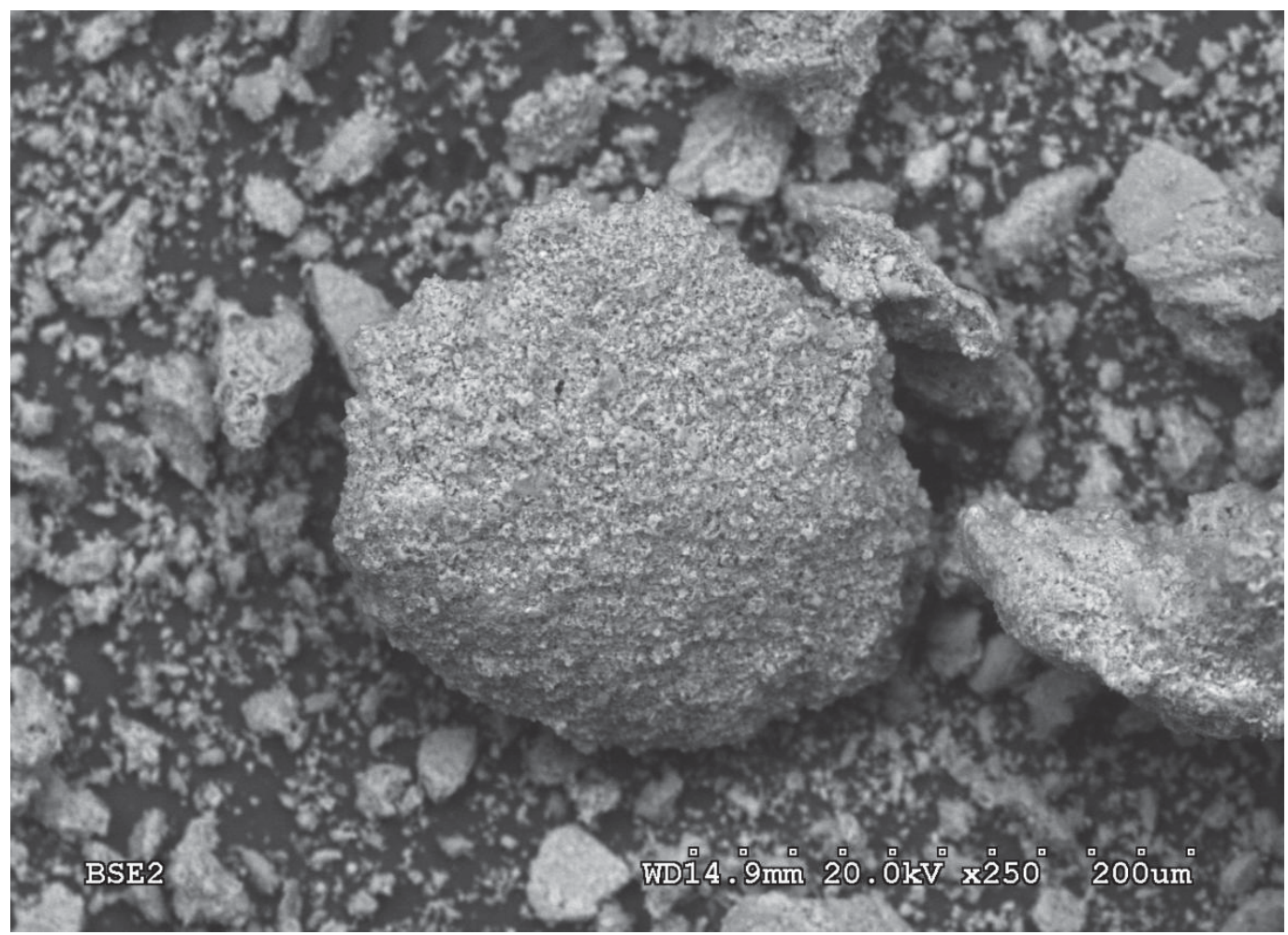

Figure 2. SEM micrograph showing a large PSA particle 


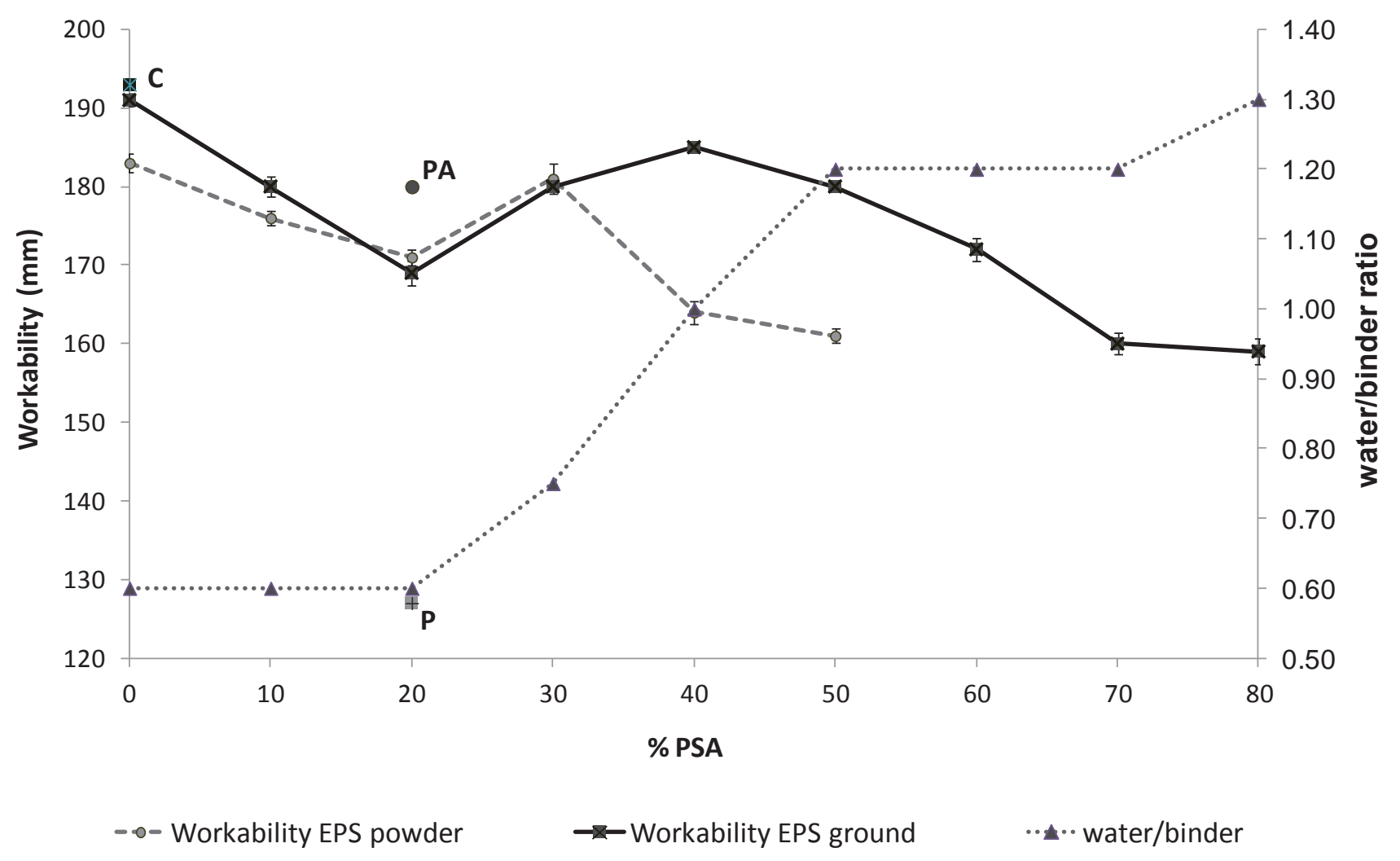

Figure 3. Effect of PSA on the workability and water/binder ratio used in mortars $\mathrm{C}=0 \% \mathrm{EPS}+0 \% \mathrm{PSA} ; \mathrm{P}=0 \% \mathrm{EPS}+20 \% \mathrm{PSA} ; \mathrm{PA}=0 \% \mathrm{EPS}+20 \% \mathrm{PSA}+$ additives 


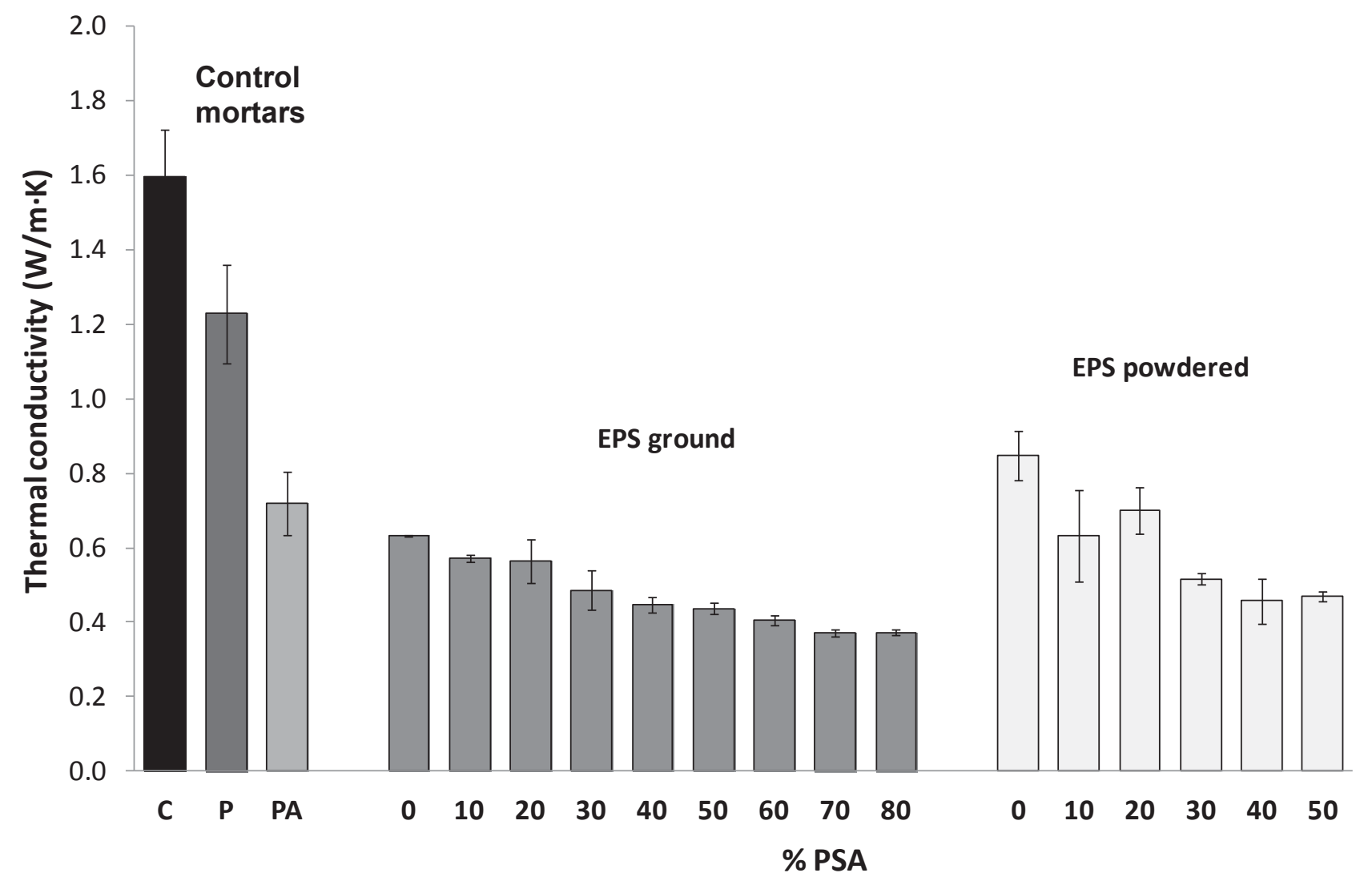

Figure 4. Effect of PSA addition on thermal conductivity of mortars samples with $60 \% \mathrm{v} / \mathrm{v} \%$ of sand added by EPS, where the control mortars were: $C=0 \% E P S+0 \% P S A ; P=0 \% E P S+20 \% P S A ; P A=0 \% E P S+20 \% P S A$ +additives 


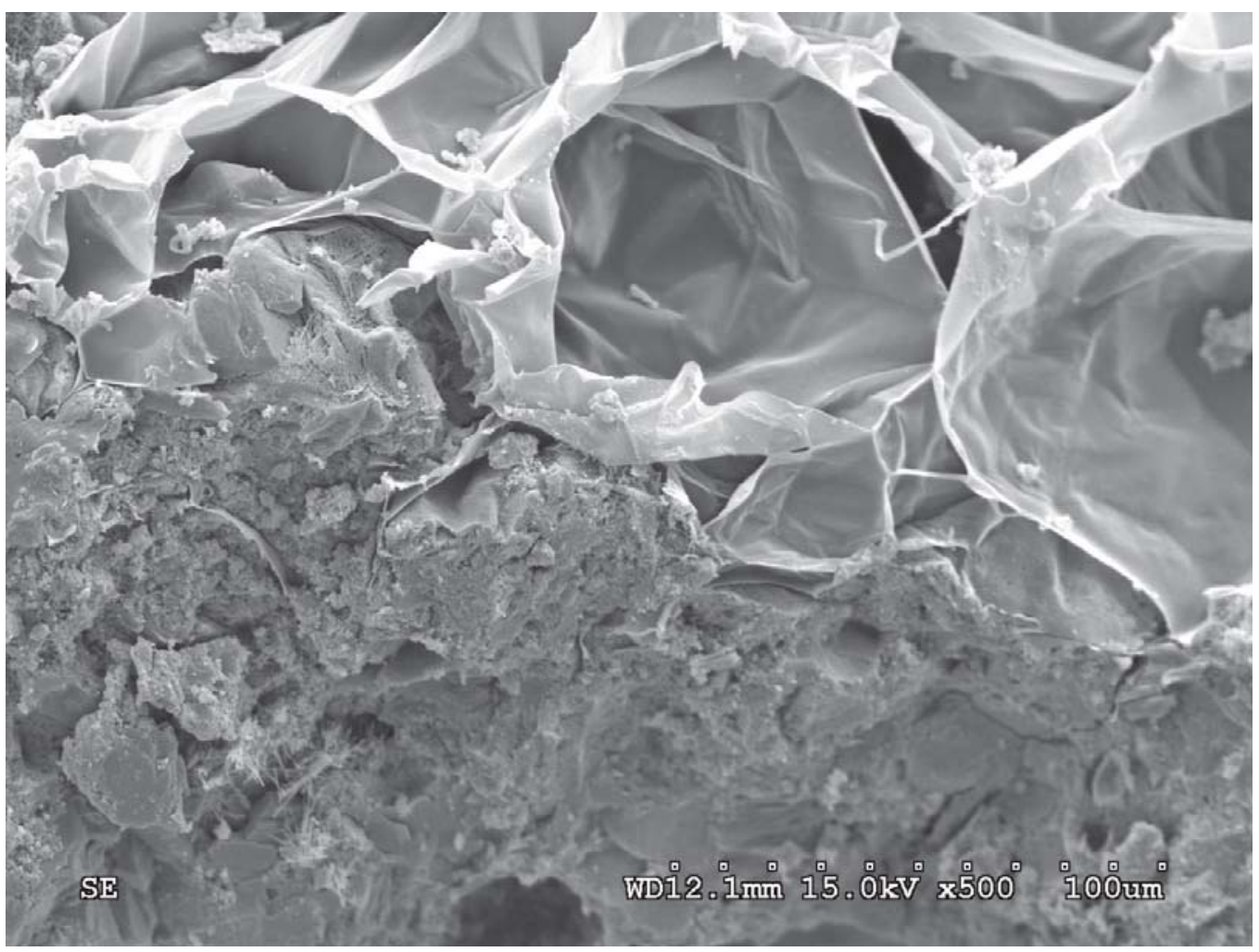

Figure 5a. SEM image of sample p30PSA showing powered EPS particles in mortar matrix

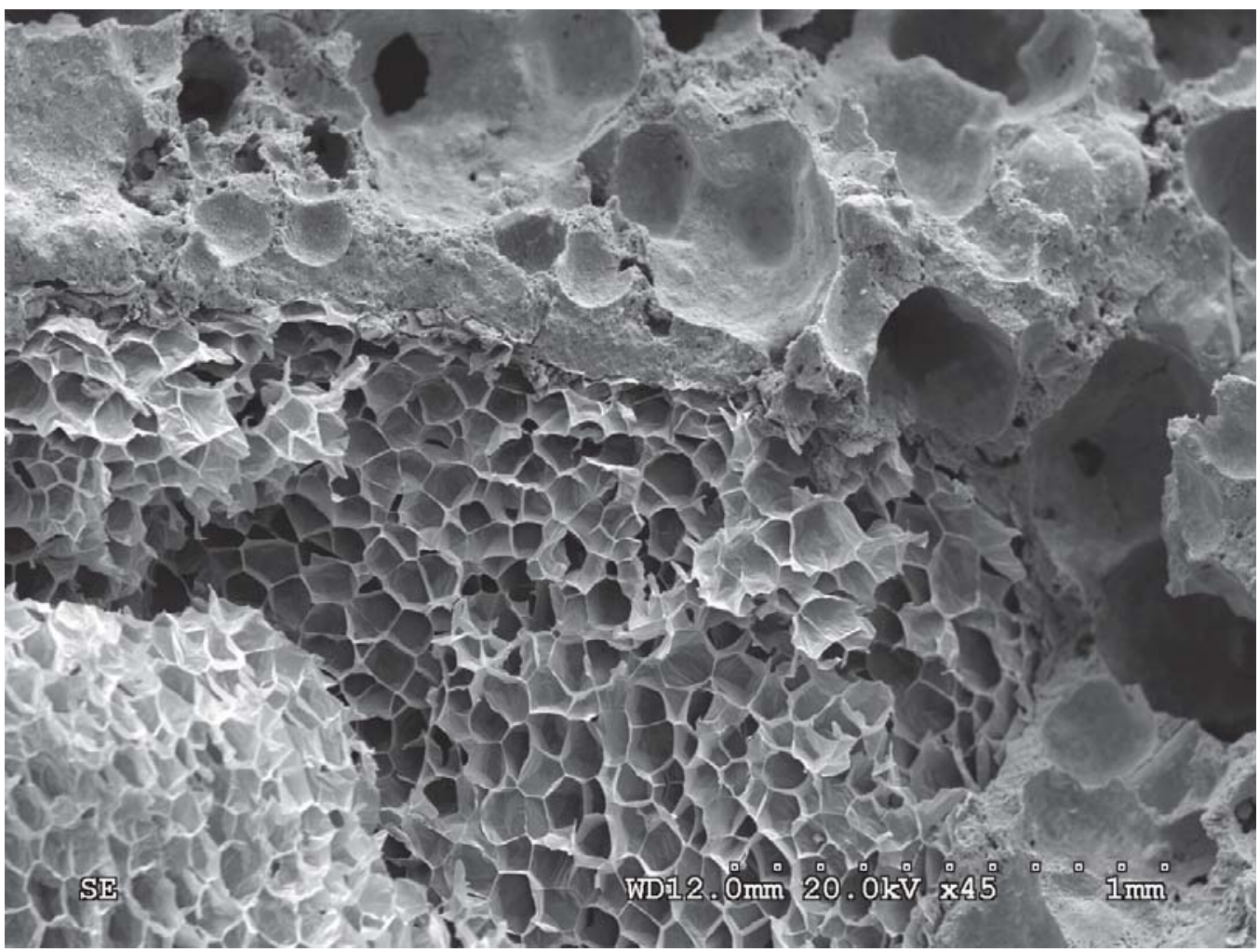

Figure 5b. SEM image of sample g30PSA showing a ground EPS particle in mortar matrix 


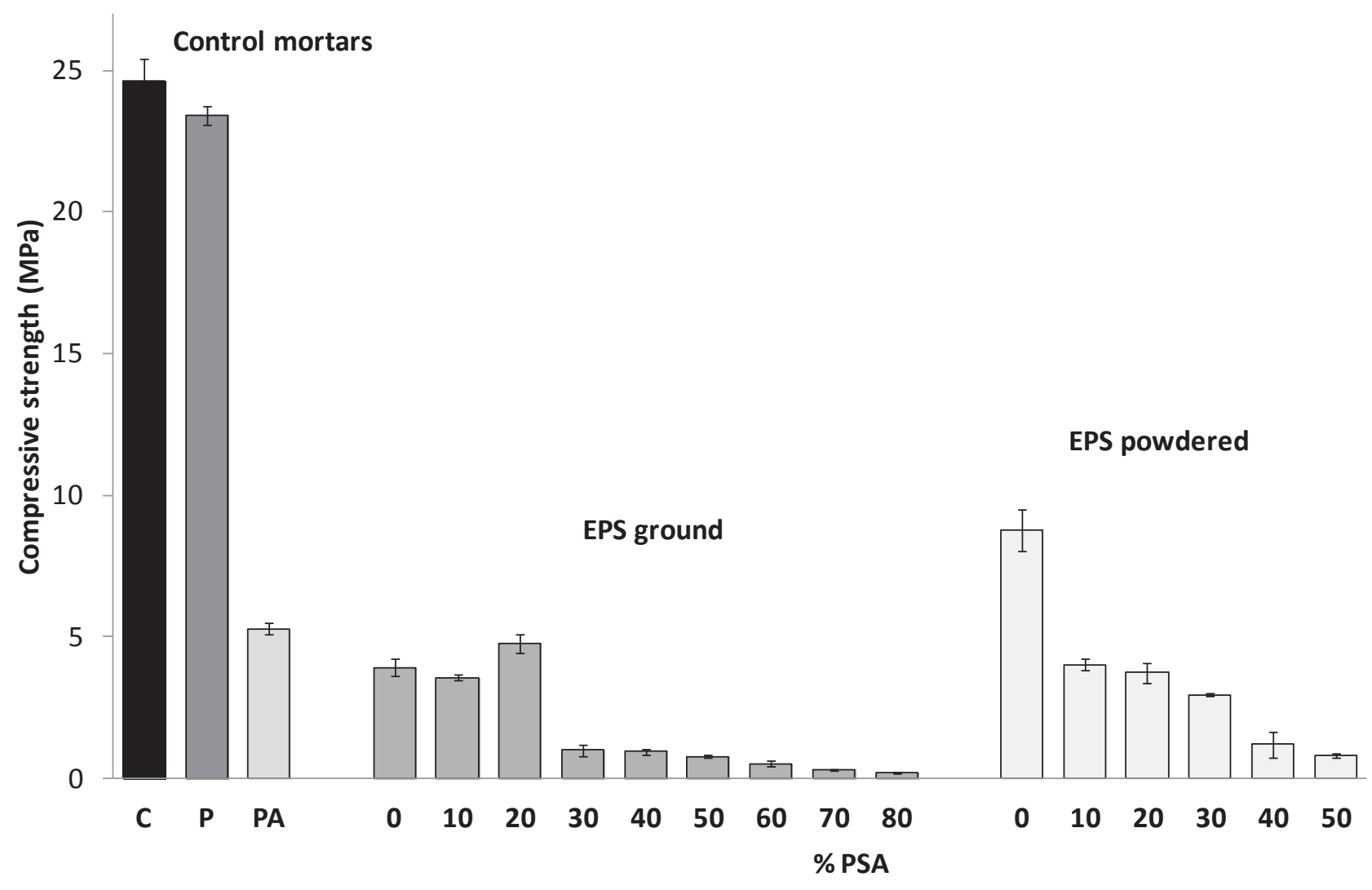

Figure 6. Effect of PSA addition on the compressive strength of mortar samples with $60 \mathrm{v} / \mathrm{v} \%$ of sand added by EPS, where the control mortars were: $C=0 \% E P S+0 \% P S A ; P=0 \% E P S+20 \% P S A ; P A=0 \% E P S+20 \% P S A$ +additives 
Click here to download Table: Tables_V.Ferrandiz_etal.docx

\section{Table 1}

Chemical Composition of Portland cement and PSA determined by XRF, as oxides (>0.1wt.\%)

\begin{tabular}{ccccccccccc}
\hline wt.\% & $\mathrm{CaO}$ & $\mathrm{SiO}_{2}$ & $\mathrm{Al}_{2} \mathrm{O}_{3}$ & $\mathrm{Fe}_{2} \mathrm{O}_{3}$ & $\mathrm{SO}_{3}$ & $\mathrm{MgO}$ & $\mathrm{K}_{2} \mathrm{O}$ & $\mathrm{Na}_{2} \mathrm{O}$ & $\mathrm{TiO}_{2}$ & $\mathrm{P}_{2} \mathrm{O}_{5}$ \\
\hline CEM II/A-LL 32,5R & 62.88 & 15.07 & 3.40 & 2.26 & 3.18 & 1.42 & 0.56 & 0.36 & 0.20 & 0.19 \\
\hline PSA & 54.20 & 20.46 & 12.10 & 0.82 & 0.40 & 3.38 & 0.42 & 0.21 & 0.32 & 0.28 \\
\hline
\end{tabular}


Table 2

Composition of mortar samples containing expanded polystyrene (EPS) and paper sludge ash (PSA).

\begin{tabular}{|c|c|c|c|c|c|c|}
\hline & Sample ID & Cement & $\begin{array}{c}\text { Paper } \\
\text { Sludge Ash }\end{array}$ & EPS & $\begin{array}{c}\text { Binder/sand } \\
\text { ratio }\end{array}$ & $\begin{array}{l}\text { Water/binder } \\
\text { ratio }\end{array}$ \\
\hline & & $\% w / w$ & $\begin{array}{l}\% w / w \\
\text { cement }\end{array}$ & $\begin{array}{l}\% \mathrm{v} / \mathrm{v} \\
\text { sand }\end{array}$ & & \\
\hline $\begin{array}{l}\text { Control mortar } \\
\text { (0\%EPS, 0\%PSA) }\end{array}$ & $C$ & 100 & 0 & 0 & 0.33 & 0.60 \\
\hline $\begin{array}{c}\text { Control mortar } \\
\text { (0\% EPS, 20\%PSA) }\end{array}$ & $P$ & 80 & 20 & 0 & 0.33 & 0.60 \\
\hline $\begin{array}{c}\text { Control mortar } \\
\text { (0\% EPS, 20\%PSA, } \\
0.8 \mathrm{~A} / 0.1 \mathrm{R} / 0.8 \mathrm{~S} / 6 \mathrm{~V})\end{array}$ & PA & 80 & 20 & 0 & 0.33 & 0.60 \\
\hline \multirow{9}{*}{$\begin{array}{c}\text { EPS ground } \\
(0.4 \mathrm{~A} / 0.1 \mathrm{R} / 0.5 \mathrm{~S} / 6 \mathrm{~V})\end{array}$} & gOPSA & 100 & 0 & 60 & 0.33 & 0.60 \\
\hline & g10PSA & 90 & 10 & 60 & 0.33 & 0.60 \\
\hline & g20PSA & 80 & 20 & 60 & 0.33 & 0.60 \\
\hline & g30PSA & 70 & 30 & 60 & 0.33 & 0.75 \\
\hline & g40PSA & 60 & 40 & 60 & 0.33 & 1.00 \\
\hline & g50PSA & 50 & 50 & 60 & 0.33 & 1.20 \\
\hline & g60PSA & 40 & 60 & 60 & 0.33 & 1.20 \\
\hline & g70PSA & 30 & 70 & 60 & 0.33 & 1.20 \\
\hline & g80PSA & 20 & 80 & 60 & 0.33 & 1.30 \\
\hline \multirow{6}{*}{$\begin{array}{c}\text { EPS powdered } \\
(0.8 \mathrm{~A} / 0.1 \mathrm{R} / 0.8 \mathrm{~S} / 6 \mathrm{~V})\end{array}$} & pOPSA & 100 & 0 & 60 & 0.33 & 0.60 \\
\hline & p10PSA & 90 & 10 & 60 & 0.33 & 0.60 \\
\hline & p2OPSA & 80 & 20 & 60 & 0.33 & 0.60 \\
\hline & p30PSA & 70 & 30 & 60 & 0.33 & 0.75 \\
\hline & p40PSA & 60 & 40 & 60 & 0.33 & 1.00 \\
\hline & p50PSA & 50 & 50 & 60 & 0.33 & 1.20 \\
\hline
\end{tabular}

Note: EPS in addition of sand

$A=$ air-entraining agent (BASF Rheomix 934)

$\mathrm{R}$ = water retaining additive (Hydroxypropyl methylcellulose TER CELL HPMC 15 MS PF)

$\mathrm{S}$ = superplastizicer (BASF Rheomix GT $205 \mathrm{MA}$ )

$\mathrm{V}=$ dispersible polymer (VINNAPAS 5028E) 
Table 3

Dry bulk density of mortars containing EPS and paper sludge ash as well as for control mortars

\begin{tabular}{|c|c|c|c|}
\hline EPS type & Sample ID & Water/binder & Bulk density $\left(\mathrm{g} / \mathrm{cm}^{3}\right)$ \\
\hline \multirow{3}{*}{ Control mortars } & $\mathrm{C}$ & 0.60 & $2.05 \pm 0.01$ \\
\hline & $\mathrm{P}$ & 0.60 & $1.98 \pm 0.01$ \\
\hline & PA & 0.60 & $1.23 \pm 0.07$ \\
\hline \multirow{9}{*}{ EPS ground } & gOPSA & 0.60 & $1.06 \pm 0.02$ \\
\hline & g10PSA & 0.60 & $1.05 \pm 0.01$ \\
\hline & g20PSA & 0.60 & $1.21 \pm 0.02$ \\
\hline & g30PSA & 0.75 & $0.92 \pm 0.01$ \\
\hline & g40PSA & 1.00 & $1.01 \pm 0.03$ \\
\hline & g50PSA & 1.20 & $1.10 \pm 0.03$ \\
\hline & g60PSA & 1.20 & $0.98 \pm 0.02$ \\
\hline & g70PSA & 1.20 & $0.95 \pm 0.02$ \\
\hline & g80PSA & 1.30 & $0.88 \pm 0.01$ \\
\hline \multirow{6}{*}{ EPS powdered } & pOPSA & 0.60 & $1.46 \pm 0.06$ \\
\hline & p10PSA & 0.60 & $1.17 \pm 0.04$ \\
\hline & p20PSA & 0.60 & $1.24 \pm 0.03$ \\
\hline & p30PSA & 0.75 & $1.23 \pm 0.04$ \\
\hline & p40PSA & 1.00 & $1.18 \pm 0.01$ \\
\hline & p50PSA & 1.20 & $1.13 \pm 0.02$ \\
\hline
\end{tabular}


Table 4

Comparison of mortars with relevant EU standards

\begin{tabular}{|c|c|c|c|}
\hline \multirow[t]{2}{*}{ EPS type } & \multirow[t]{2}{*}{ Sample ID } & \multicolumn{2}{|c|}{ Standard } \\
\hline & & EN 998-1 & EN 998-2 \\
\hline \multirow{3}{*}{$\begin{array}{l}\text { Control } \\
\text { mortars }\end{array}$} & C & CSIV & M20 \\
\hline & $\mathrm{P}$ & CSIV & $\mathrm{M} 20$ \\
\hline & PA & CSIII & M5 \\
\hline \multirow{9}{*}{ EPS ground } & gOPSA & CSIII, CSII & M2.5 \\
\hline & g10PSA & CSIII, CSII & M2.5 \\
\hline & g20PSA & CSIII, CSII & M2.5 \\
\hline & g30PSA & CSI & M1 \\
\hline & g40PSA & $\mathrm{CSI}$ & - \\
\hline & g50PSA & $\mathrm{CSI}$ & - \\
\hline & g60PSA & CSI & - \\
\hline & g70PSA & - & - \\
\hline & g80PSA & - & - \\
\hline \multirow{6}{*}{ EPS powdered } & pOPSA & CSIV & M5 \\
\hline & p10PSA & CSIII, CSII & M2.5 \\
\hline & p20PSA & CSIII, CSII & M2.5 \\
\hline & p30PSA & CSII & M2.5 \\
\hline & p40PSA & CSI & M1 \\
\hline & p50PSA & CSI & - \\
\hline
\end{tabular}

